\title{
Compact Rectangular Microstrip Patch Antenna using Slots
}

\author{
Juin Acharjee \\ Assistant Professor, ECE, NSHM Knowledge Campus-Durgapur, West Bengal, India
}

\begin{abstract}
In this Paper a rectangular shaped Microstrip Patch antenna with special shaped slots is presented. The conventional antenna operates in the WLAN frequency band $5.22 \mathrm{GHz}$ with high gain. After introducing some special shaped slots in the conventional structure frequency of the patch antenna shifts from $5.22 \mathrm{GHz}$ to $3.17 \mathrm{GHz}$ with gain $1.8 \mathrm{dBi}$.
\end{abstract}

Keywords: Compact rectangular Microstrip antenna, Slots, Feed Point, WLAN

\section{INTRODUCTION}

For radio system antenna is an essential part and it can be defined as a device which can effectively radiate and receive electromagnetic energy. Now a days microstrip Patch antenna has attracted its attention due to its light weight, low profile, ease of fabrication. Microstrip patch antnn also gives very good compatibility in planar structure as well as in non planar structure. The only disadvantege of the antenna is it has very narrow bandwidth. In recent years, with increasing demand of small portable devices, small antenna design is also increased. Design of small size antenna with low frequency and high gain becomes a very challenging task for every researchers. Many kind of miniaturization techniques such as slot cutting on radiating patch or adding defected ground structure on ground plane have been proposed by various authors. In this paper slot cutting techniques has been adopted to shift the frequency from high to low. This design incorporate a special shaped slot on the patch which changes the current direction path on the radiating slot and due to this reason that antenna radiating at different frequency. Initially the antenna is designed with resonating frequency $5.2 \mathrm{GHz}$ after that cutting slot on the patch the resonating frequency of the antenna is shifted down to $3.17 \mathrm{GHz}$.

\section{ANTENNA DESIGN}

The geometry of the proposed antenna is shown in Fig. 2. The Length and width of the conventional antenna is $12.8 \mathrm{~mm}$ and $17.24 \mathrm{~mm}$. The substrate of dielectric constant 2.7 and dielectric loss tangent of 0.0001 has been taken in this design. Method of Moment based IE3D software has been taken to design and simulate the design. Initially one $17.24 \mathrm{~mm}$ length and $12.8 \mathrm{~mm}$ width rectangular patch has been taken. To simulate that patch antenna at $5.2 \mathrm{GHz}$ feed point location is chosen at $(0,-2.22)$. After designing the conventional antenna at $5.2 \mathrm{GHz}$ two different shaped slots have been taken to shift down the frequency to 3.17 $\mathrm{GHz}$ at the same structure. Different parameter values of proposed antenna are shown in the Table 1
TABLE I

DIFFERENT PARAMETER VALUES OF PROPOSED ANTENNA

\begin{tabular}{|l|c|}
\hline Parameters & Values(in mm) \\
\hline A & 7.4 \\
\hline B & 1.37 \\
\hline C & 2.85 \\
\hline D & 1.17 \\
\hline E & 0.4 \\
\hline F & 2.62 \\
\hline G & 7 \\
\hline H & 5.2 \\
\hline I & 2.2 \\
\hline J & 2.2 \\
\hline K & 0.4 \\
\hline L & 12.8 \\
\hline W & 17.24 \\
\hline
\end{tabular}

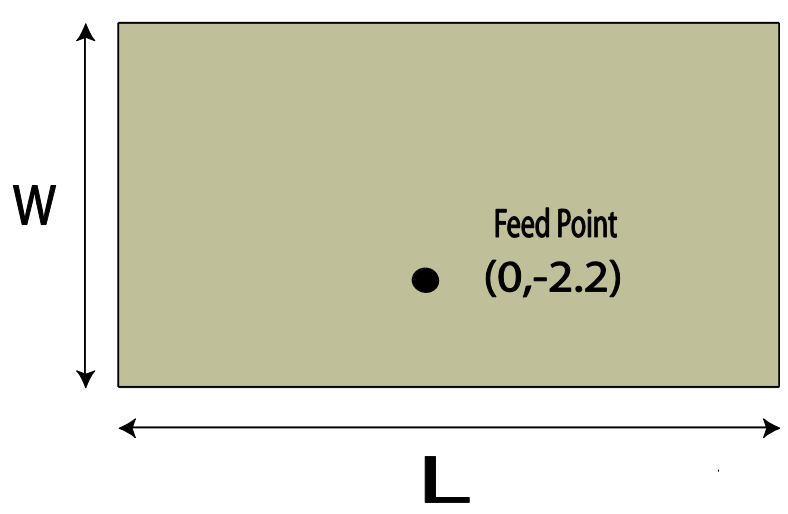

Fig. 1. Rectangular Patch 
International Journal of Advanced Research in Computer and Communication Engineering

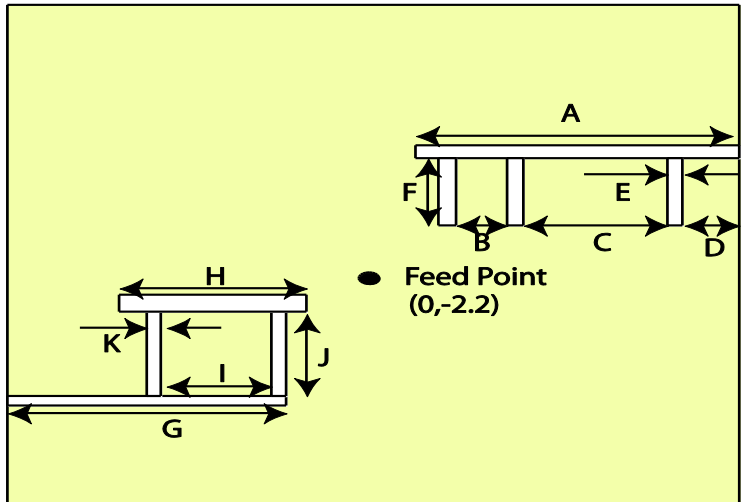

Fig. 2.Radiating Patch with Slots

\section{III.SIMULATION RESULTS}

Return loss and Voltage Standing Wave Ratio(VSWR) of the conventional antenna and antenna with slots are shown in figure 3, 4, 5 and 6 . Figure 3 and 4 shows the return loss of the conventional antenna and antenna with slots. Return loss of the conventional antenna at the resonating frequency $5.2 \mathrm{GHz}$ is $-24.82 \mathrm{~dB}$ and return loss of the antenna with slots at the resonating frequency $3.17 \mathrm{GHz}$ is -22.57 .

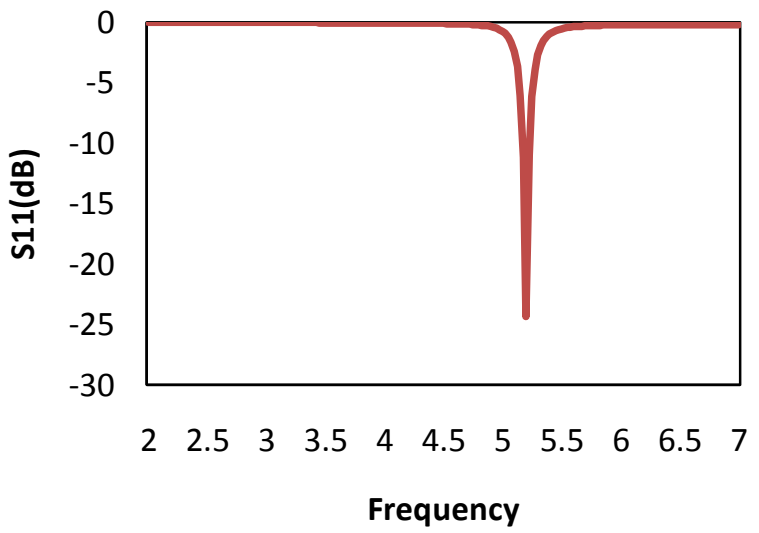

Fig. 3. Return Loss of the Conventional Rectangular Patch Antenna

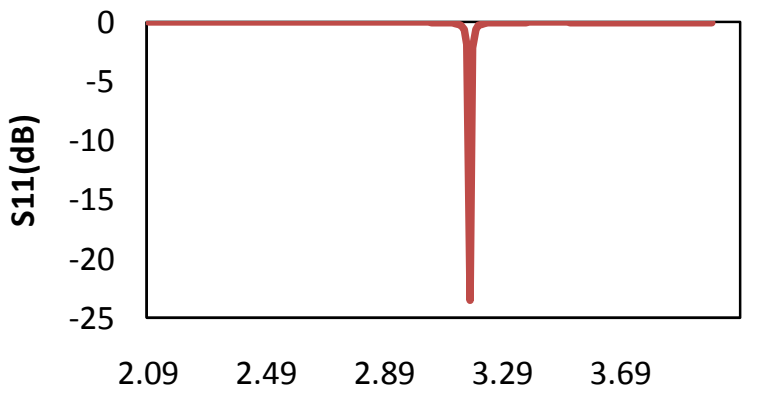

\section{Frequency}

Fig. 4. Return loss of the patch antenna with Slots

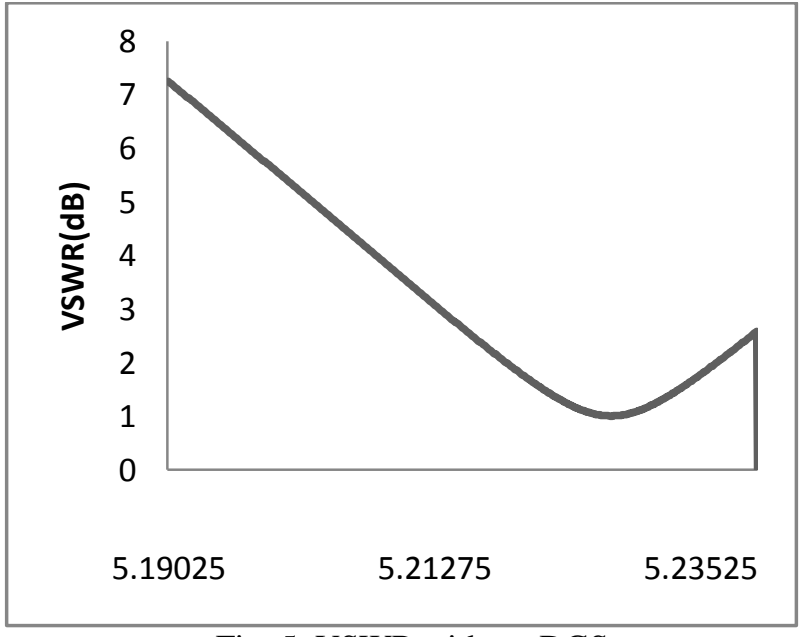

Fig. 5. VSWR without DGS

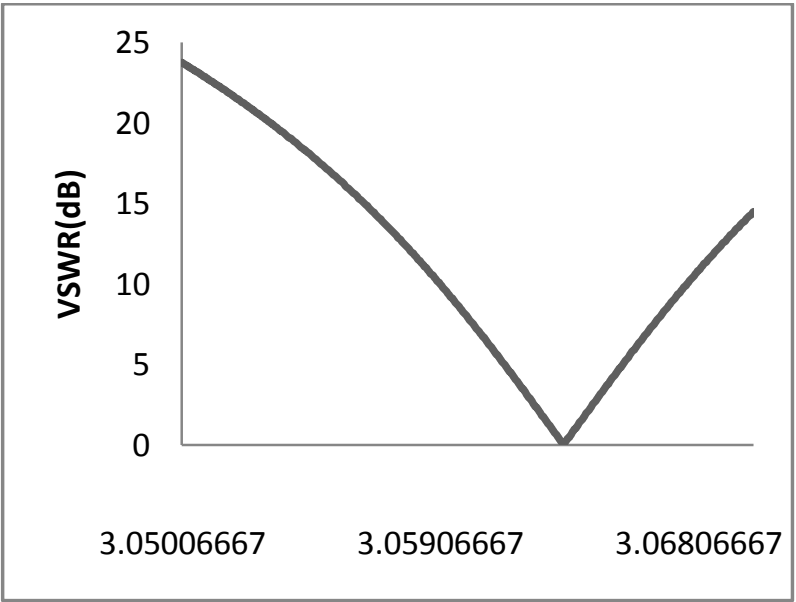

Fig.6.VSWR with Slots

This antenna radiates maximum to its normal direction. Radiation pattern of the conventional antenna for $\varphi=0$ and $\varphi=90$ degree is shown in the figure 7. Similarly the radiation pattern for $\varphi=0$ and $\varphi=90$ degree of the slotted antenna is shown in the figure 8 . $3 \mathrm{~d}$ radiation pattern of theses two antennas are shown in the figure 9 and 10which shows both conventional and slotted antenna have high gain and that are 6.3 and $1.87 \mathrm{dBi}$.

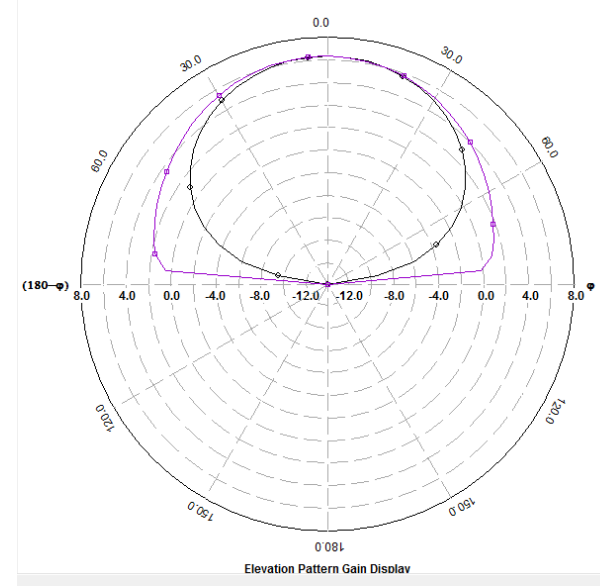

Fig 7. 2D Radiation Pattern Of Conventional Antenna at $5.20 \mathrm{GHz}$ 


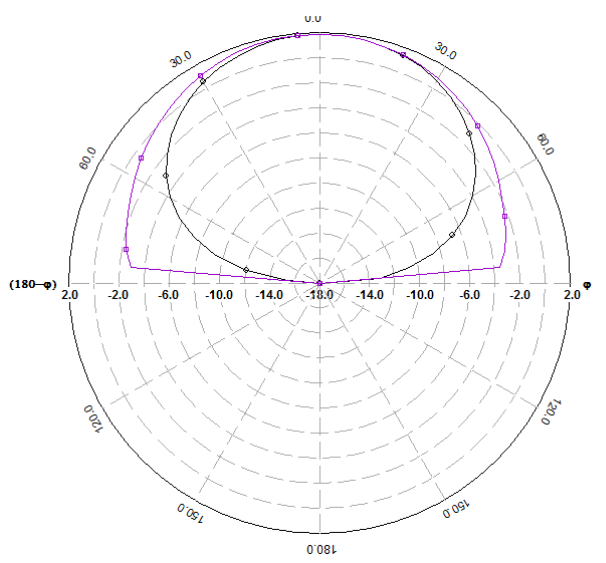

Fig. 8. 2D Radiation Pattern with slot at $3.17 \mathrm{GHz}$

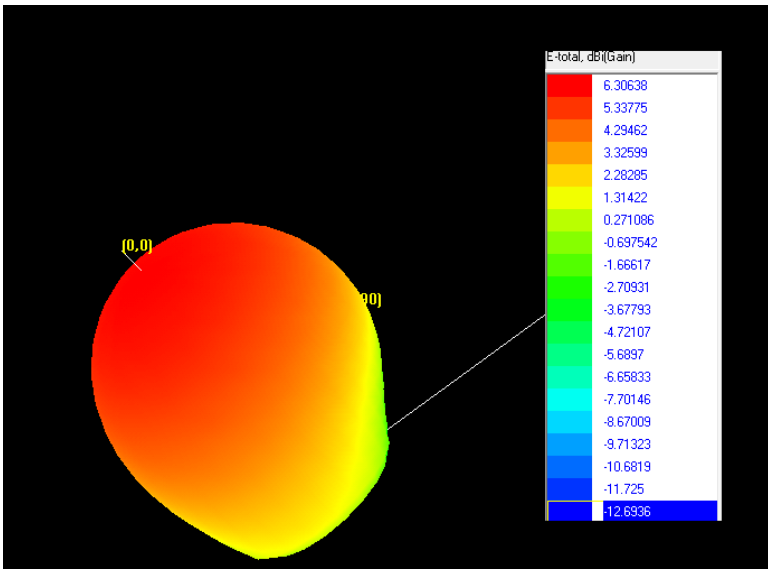

Fig. 9. 3D Input Gain without Slots

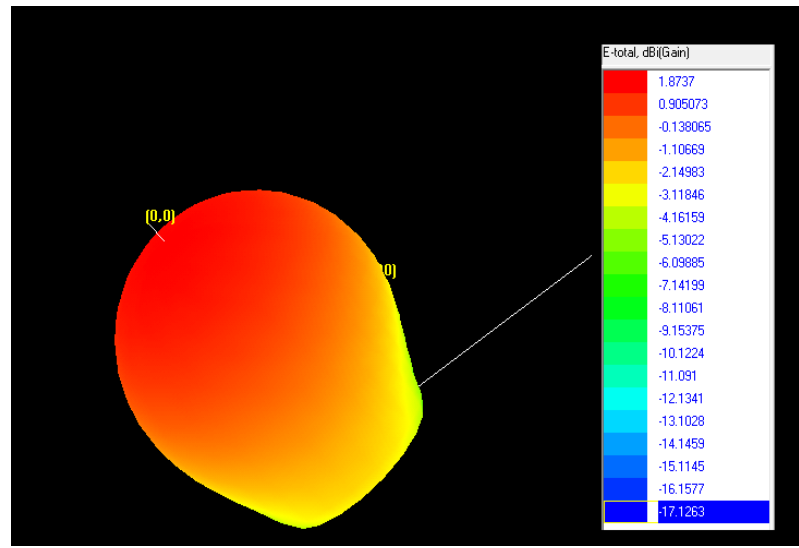

Fig. 10. 3D Input Gain with Slots

\section{IV.CONCLUSION}

In this paper a rectangular slotted antenna design has been proposed. By introducing special shaped slots on the radiating patch of the conventinal antenna which resonates at $5.2 \mathrm{GHz}$ shifts the resonating frequency to $3.17 \mathrm{GHz}$ with gain $1.87 \mathrm{dBi}$ and good radiation characteristics.

\section{REFERENCES}

[1] A.K. Skrivernilk,Zurcher O. Staub and J.R. Mosig,'PCS antenna design: The challenge of miniatururization" IEEE Antenna Propagation Magazine, 43 (4), pp 12-27, August 2011M. Young, The Techincal Writers Handbook. Mill Valley, CA: University Science, 1989.

[2] J. -Y. Jan and L. -C. Tseng, " Small planar monopole Antenna with a shorted parasitic inverted-L wire for Wireless communications in the 2. 4, 5. 2 and 5. $8 \mathrm{GHz}$. bands", IEEE Trans. Antennas and Propag., VOL. 52, NO. 7, July 2004, pp -1903-1905.

[3] K.-L. Wong, Compact and Broadband Microstrip antennas. New York: Wiley-Interscience,2002, p.5

[4] H. M. Heo and J. M.Woo, "Miniaturization of microstrip antenna using folded structure," in Proc. Int. Symp. Antennas Propag., endai,Japan, Aug. 2004, pp. 985-988

[5] Zhang, Z., M. F. Iskander, J.-C. Langer, and J. Mathews, "Dualband WLAN dipole antenna using an internal matching circuit," IEEE Trans. Antennas and Propag., Vol. 53, No. 5, 1813-1818,May 2005

[6] Arya, A.K. Kartikeyan, M.V., Patnaik, A., "Efficiency enhancement of microstrip patch antennas with Defected Ground Structure,'IEEE proc. Recent Advanced in Microwave theory and applications (MICROWAVE-08), pp.729-731 November 2008.

[7] Zeland Software Inc. IE3D: MoM-Based EM Simulator. Web: http://www. zeland. com/

\section{BIOGRAPHY}

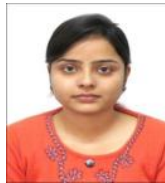

Juin Acharjee was born in Born 1989. She has done M.Tech from West Bengal university of Technology in 2013.Presently She is working as an Assistant Professor in the Dept of ECE at NSHM Knowledge Campus, Durgapur, West Bengal, India. Her research interests are in Microstrip Patch Antenna, FSS, and Communication system. 